\title{
Design and Applied Systematic Matrix Method for Orthogonal MIMO Channel over Fading Channel
}

\author{
Hemlata Sinha ${ }^{1}$, M.R. Meshram ${ }^{2}$ and G.R. Sinha ${ }^{3}$ \\ ${ }^{1}$ Research Scholar, Shri Shankaracharya Technical Campus Bhilai, Chhattisgarh, India \\ ${ }^{2}$ Associate Professor, Department of Electronics and Telecommunication Engineering, Government Engineering College, \\ Jagdalpur, Chhattisgarh, India \\ ${ }^{3}$ Adjunct Professor, IIIT Bangalore, Karnataka, India \\ E-Mail: Sinha.hemlata552@gmail.com_meshram_66@yahoo.co.in_drgrsinha@ieee.org
}

\begin{abstract}
In this paper we propose a systematic method for designing a space - time orthogonal MIMO scheme that employs an arbitrary number of transmitting and receiving antennas. Such systems is utilized to improve the bit error rate (BER) performance of wireless communication systems and counter the destructive effects of channel attenuation and alternative distortion phenomena and also propose a matrix method advance is proposed to maintain the orthogonal property, which is most essential, so that the channels may remain un correlated, due to this condition, interference do not occurs between the data transmitted through the channels and thus performance improvement is achieved, which is evaluated through simulation.

Keywords: MIMO, BER, STBC
\end{abstract}

\section{INTRODUCTION}

During early days, in wireless communication system a sender uses a single antenna to transmit a signal, which after undergoing modification effects in the communication channel, is received by a single antenna at the receiver. In a Multiple Input and Multiple Output (MIMO) scheme, as the name suggests, the sender uses multiple antennas for transmission and the receiver uses multiple antennas for reception, thus making available multiple communication paths or channels between the sender and receiver. These multiple channels can be used to increase the data rate by sending different data streams on the different channels [3]. But another perhaps a better way is to transmit different blocks, containing encoded data, in different channels. This procedure known as Space Time Block Coding (STBC) the bit error rate (BER) performance at lower SNR at the receiver can be improved. Error performance gets adversely effected at higher data rates, an additional study is been made to analyze the amount of degradation in BER at higher data rates (QAM) with respect to lower data rates (BPSK) [2].

In this paper we focus on the use of MIMO systems to improve the BER performance of wireless communication systems in fading channels as well as in channels based on actual field measurements. In a fading channel, the transmitted signal is reflected, diffracted or scattered in the channel, and, as a consequence, attenuated "versions" of the symbol arrive at the receiver via multiple paths and at varying times, causing unpredictable time-varying changes in the magnitude and phase of the arriving received signal. Real-world channels will also exhibit Doppler spread and co-channel interference as well.

We propose a systematic method for designing multi antenna system. The biggest challenge is to create orthogonal behavior between the channels, so that no correlation may exist between the channels. A manuscript work presented by Alamouti [1] proposed a method to maintain orthogonal behavior, which is known as space time block coding. In multi antenna system, the number of independent channels that a signal passes through, from the sender to the receiver is termed diversity gain. The maximum diversity gain is the product of the number of transmitting antennas and the number of receiving antennas; with assumption that all signal paths are orthogonal (independent) due to use of STBC [4][9]. We study the effect of various diversity gain Thus we also discuss orthogonal behavior in detail. The performance of digital system is primarily measured by Power efficiency, Bandwidth efficiency and the error performance of the system [10]. This paper studies the performance of a variety of MIMO schemes in channels exhibiting fading and other distortion phenomena. We show that by properly designing the system to meet orthogonality conditions, a system employing multiple antennas can achieve a markedly improved bit error rate. We propose a systematic process for designing a MIMO system with an arbitrary number of transmitting antennas and receiving antennas, and evaluate (through simulation) the performance improvements that can be attained by employing our design approach [7].

\section{SYSTEMATIC DESIGN OF MIMO SYSTEMS}

\section{A. Two Transmitter-One Receiver System Scheme (Alamouti Scheme)}

In this scheme two antennas are used for transmitting and one antenna for receiving. The diversity gain is two times than that of the single input single output (SISO) system. In this scheme, two symbols $\mathrm{x} 1$ and $\mathrm{x} 2$ are transmitted during 
first two time intervals as follows the symbols $\mathrm{x} 1$ and $\mathrm{x} 2$ are transmitted simultaneously by using antenna 1 a nd 2 respectively, during first time interval and during second time interval $-\mathrm{x} 2 *$ and $\mathrm{x} 1 *$ are transmitted simultaneously, by using the same arrangement of a ntenna 1 and 2 respectively[1]. Complex conjugate is represented by asterisk

$$
\mathrm{X}=\operatorname{Tx} \underset{\text { Time slots }}{\left[\begin{array}{cc}
\mathrm{x}_{1} & -\mathrm{x}_{2}^{*} \\
\mathrm{x}_{2} & \mathrm{x}_{1}^{*}
\end{array}\right]} \underset{\longrightarrow}{\longrightarrow}
$$

The same process is repeated to transmit next two symbols, and so on. Four symbols $\mathrm{x} 1, \mathrm{x} 2, \mathrm{x} 3$ and $\mathrm{x} 4$ will take four consecutive time slots as shown in figure1. Two symbols are encoded as a block.

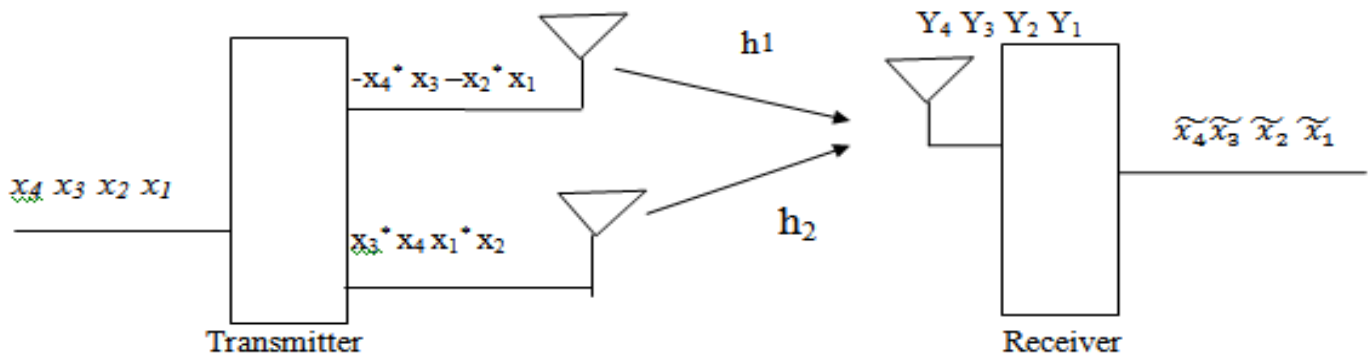

Fig. 1 Two transmitter-one receiver scheme

The received signals y1 and y 2 are composed of signals from antenna 1 and 2 , in addition with additive noise.

$$
\begin{aligned}
& \mathrm{y} 1=\mathrm{h} 1 \mathrm{x} 1+\mathrm{h} 2 \mathrm{x} 2+\mathrm{n} 1 \\
& \mathrm{y} 2=-\mathrm{h} 1 \mathrm{x} 2 *+\mathrm{h} 2 \mathrm{x} 1 *+\mathrm{n} 2
\end{aligned}
$$

Where $\mathrm{n} 1$ and $\mathrm{n} 2$ represents additive noise and $\mathrm{h} 1, \mathrm{~h} 2$ represent channel gain. We assume memory less and flat channel, it is also assumed that the receiver has complete channel state information (CSI), therefore the receiver can determine and calculate $\mathrm{h} 1$ and $\mathrm{h} 2$.

The receiver then calculates estimated $\mathrm{x} 1$ and $\mathrm{x} 2$, denoted by $\widetilde{\mathrm{x}_{1}}$ and $\widetilde{\mathrm{x}_{2}}$, by processing of $\mathrm{y} 1$ and $\mathrm{y} 2$ as follows,

$$
\begin{aligned}
& \widetilde{\mathrm{x}_{1}}=\mathrm{h} 1 * \mathrm{y} 1+\mathrm{h} 2 \mathrm{y} 2 * \\
& \widetilde{\mathrm{x}_{2}}=\mathrm{h} 2 * \mathrm{y} 1-\mathrm{h} 1 \mathrm{y} 2 *
\end{aligned}
$$

substituting the values of y1 and $\mathrm{y} 2$, we get

$$
\begin{gathered}
\widetilde{\mathrm{x}_{1}}=\mathrm{h}_{1}{ }^{*} \mathrm{y}_{1}+\mathrm{h}_{2} \mathrm{y}_{2}{ }^{*}=\left(\left|\mathrm{h}_{1}\right|^{2}+\left|\mathrm{h}_{2}\right|^{2}\right) \mathrm{x}_{1}+\mathrm{h}_{1}{ }^{*} \mathrm{n}_{1}+\mathrm{h}_{2} \mathrm{n}_{2}{ }^{*} \\
\widetilde{\mathrm{x}_{2}}=\mathrm{h}_{2}{ }^{*} \mathrm{y}_{1}-\mathrm{h}_{1} \mathrm{y}_{2}{ }^{*}=\left(\left|\mathrm{h}_{1}\right|^{2}+\left|\mathrm{h}_{2}\right|^{2}\right) \mathrm{x}_{2}+\mathrm{h}_{2}{ }^{*} \mathrm{n}_{1}-\mathrm{h}_{1} \mathrm{n}_{2}{ }^{*}
\end{gathered}
$$

Thus the estimated signal $\widetilde{\mathrm{x}_{1}}$ and $\widetilde{\mathrm{x}_{2}}$, thus the received signal $\widetilde{x_{1}}$ and $\widetilde{x_{2}}$ are proportional to the $x_{1}$ and $x_{2}$ in presence of noise. Fading in any channel will affect both the values in same manner. In matrix form

$$
\left[\begin{array}{c}
\mathrm{y}_{1} \\
\mathrm{y}_{2}{ }^{*}
\end{array}\right]=\left[\begin{array}{cc}
\mathrm{h}_{1} & \mathrm{~h}_{2} \\
\mathrm{~h}_{2}{ }^{*} & -\mathrm{h}_{1}{ }^{*}
\end{array}\right]\left[\begin{array}{c}
\mathrm{x}_{1} \\
\mathrm{x}_{2}{ }^{*}
\end{array}\right]=\mathrm{H}\left[\begin{array}{c}
\mathrm{x}_{1} \\
\mathrm{x}_{2}{ }^{*}
\end{array}\right]
$$

and the value of $\mathrm{H}$ (channel matrix) is given by,

$$
\mathrm{H}=\left[\begin{array}{cc}
\mathrm{h}_{1} & \mathrm{~h}_{2} \\
\mathrm{~h}_{2}{ }^{*} & -\mathrm{h}_{1}{ }^{*}
\end{array}\right]
$$

The design of channel matrix $\mathrm{H}$ is very important and it is made orthogonal, which can be verified by the relation

\section{$\mathrm{H}^{\mathrm{H}} \mathrm{H}=\mathrm{I} \quad(10)$}

Where $\mathrm{H}^{\mathrm{H}}$ is Hermitian matrix and $\mathrm{I}$ is the identity matrix. In Alamouti scheme two symbols are transmitted in two time intervals, thus rate is equal to one. Thus the channel matrix is so composed that it can be interpreted as two antennas (space diversity) by two time intervals (time diversity), preserving the orthogonality of $\mathrm{H}$ matrix and this is known as space time block code. Alamouti scheme is limited only up to two transmit antenna.

\section{B. Three Transmitter-One Receiver Scheme}

In this scheme three transmitting and one receiving antennas are present three symbols can be sent at each time interval [6]. To maintain orthogonality, the input signals are combined in different compositions (polarity and conjugate).

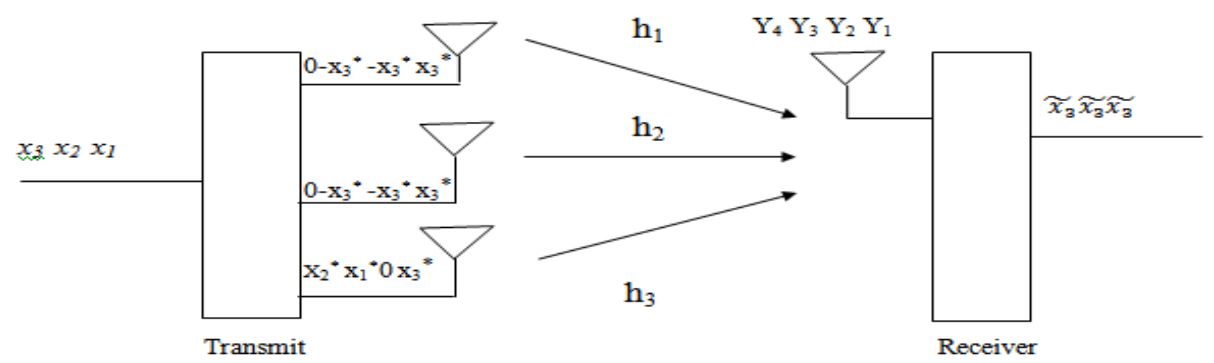

Fig 2 Three transmitter-one receiver scheme 
The matrix $\mathrm{X}$ (Transmitting matrix) is

$$
\mathrm{X}=\left[\begin{array}{cccc}
\mathrm{x}_{1} & -\mathrm{x}_{2}^{*} & \mathrm{x}_{3}^{*} & 0 \\
\mathrm{x}_{2} & \mathrm{x}_{1}^{*} & 0 & -\mathrm{x}_{3}^{*} \\
\mathrm{x}_{3} & 0 & \mathrm{x}_{1}^{*} & \mathrm{x}_{2}^{*}
\end{array}\right]
$$

The received signal will be,

$$
\begin{aligned}
& \mathrm{Y} 1=\mathrm{h} 1 \mathrm{x} 1+\mathrm{h} 2 \mathrm{x} 2+\mathrm{h} 3 \times 3+\mathrm{n} 1 \\
& \mathrm{Y} 2=\mathrm{h} 1(-\mathrm{x} 2 *)+\mathrm{h} 2 \mathrm{x} 1 *+\mathrm{h} 3(0)+\mathrm{n} 2 \\
& \mathrm{Y} 3=\mathrm{h} 1(-\mathrm{x} 3 *)+\mathrm{h} 2(0)+\mathrm{h} 3\left(\mathrm{x} 1^{*}\right)+\mathrm{n} 3 \\
& \mathrm{Y} 4=\mathrm{h} 1(0)+\mathrm{h} 2(-\mathrm{x} 3 *)+\mathrm{h} 3(\mathrm{x} 2 *)+\mathrm{n} 4
\end{aligned}
$$

Complementing the required equations,

$$
\begin{aligned}
& \mathrm{Y} 1=\mathrm{h} 1 \times 1+\mathrm{h} 2 \times 2+\mathrm{h} 3 \times 3+\mathrm{n} 1 \\
& \mathrm{Y} 2 *=(-\mathrm{h} 1 *) \times 2+\mathrm{h} 2 * \times 1+0+\mathrm{n} 2 * \\
& \mathrm{Y} 3 *=(-\mathrm{h} 1 *) \times 3+\mathrm{h} 3 *(\mathrm{x} 1)+\mathrm{n} 3 * \\
& \mathrm{Y} 4 *=(-\mathrm{h} 2 *) \times 3+\mathrm{h} 3 * \times 2+\mathrm{n} 4 *
\end{aligned}
$$

Rearranging the order of equations,

$$
\begin{aligned}
& \mathrm{Y} 1=\mathrm{h} 1 \times 1+\mathrm{h} 2 \times 2+\mathrm{h} 3 \times 3+\mathrm{n} 1 \\
& \mathrm{Y} 2 *=(-\mathrm{h} 2 *) \times 1-\mathrm{h} 1 * \mathrm{x} 2+0 \times 3+\mathrm{n} 2 * \\
& \mathrm{Y} 3 *=(-\mathrm{h} 3 *) \times 1+0 \times 2-\mathrm{h} 1 * \mathrm{x} 3+\mathrm{n} 3 * \\
& \mathrm{Y} 4 *=0 \times 1+(\mathrm{h} 3 *) \times 2-\mathrm{h} 2 * \times 3+\mathrm{n} 4 *
\end{aligned}
$$

Writing in Matrix form,

$$
\left[\begin{array}{l}
\mathrm{y}_{1} \\
\mathrm{y}_{2}^{*} \\
\mathrm{y}_{3}^{*} \\
\mathrm{y}_{4}^{*}
\end{array}\right]=\left[\begin{array}{ccc}
\mathrm{h}_{1} & \mathrm{~h}_{2} & \mathrm{~h}_{3} \\
\mathrm{~h}_{2}^{*} & -\mathrm{h}_{1}^{*} & 0 \\
\mathrm{~h}_{3}^{*} & 0 & -\mathrm{h}_{1}^{*} \\
0 & \mathrm{~h}_{3}^{*} & -\mathrm{h}_{2}^{*}
\end{array}\right]\left[\begin{array}{l}
\mathrm{x}_{1} \\
\mathrm{x}_{2} \\
\mathrm{x}_{3}
\end{array}\right]+\left[\begin{array}{l}
\mathrm{n}_{1} \\
\mathrm{n}_{2}^{*} \\
\mathrm{n}_{3}^{*} \\
\mathrm{n}_{4}^{*}
\end{array}\right]
$$

The design of $\mathrm{H}$ matrix should satisfy orthogonal condition.

$$
\mathrm{H}^{\mathrm{H}} \mathrm{H}=\left(\left|\mathrm{h}_{1}\right|^{2}+\left|\mathrm{h}_{2}\right|^{2}+\left|\mathrm{h}_{3}\right|^{2}\right) \mathrm{I}_{3}
$$

Where,

$$
\mathrm{I}_{3}=\left[\begin{array}{lll}
1 & 0 & 0 \\
0 & 1 & 0 \\
0 & 0 & 1
\end{array}\right]
$$

Since time required sending 3 symbols are 4 time intervals, thus the rate of the scheme is $(3 / 4)$.
Schematic way to design a MIMO system (Higher order MISO system):

1. The most important property of $\mathrm{H}$ matrices orthogonality which can be verified by calculating $\mathrm{H}^{\mathrm{H}} \mathrm{H}=\mathrm{I}$, where $\mathrm{HH}$ is hermitian matrix and $\mathrm{I}$ is Identity matrix.

2. Another method to verify orthogonality is that each column is orthogonal to all of the other columns.

Design process: System with $t$ transmitting and one receiving antenna is to be designed (MISO).

Design of Channel matrix-

Step1: Let the first row contains t columns

[h1 h2 h3 h4......ht]

$\{$ No. of columns $(\mathrm{t})$ gives space diversity $\}$

Step2: Addition of rows and maintaining orthogonality

$\left[\begin{array}{cccccc}\mathrm{h}_{1} & \mathrm{~h}_{2} & \mathrm{~h}_{3} & \mathrm{~h}_{4} & \ldots & \mathrm{h}_{\mathrm{t}} \\ -\mathrm{h}_{2}^{*} & -\mathrm{h}_{1}^{*} & 0 & 0 & \ldots & 0\end{array}\right]$

Step3: Third row is added and first and third column are made orthogonal.

$\left[\begin{array}{cccccc}\mathrm{h}_{1} & \mathrm{~h}_{2} & \mathrm{~h}_{3} & \mathrm{~h}_{4} & \ldots & \mathrm{h}_{\mathrm{t}} \\ -\mathrm{h}_{2}^{*} & -\mathrm{h}_{1}^{*} & 0 & 0 & \ldots & 0 \\ \mathrm{~h}_{3}^{*} & 0 & -\mathrm{h}_{1}^{*} & 0 & \ldots & 0\end{array}\right]$

Step4: Fourth row is added and first and fourth column are made orthogonal and so on.

$\left[\begin{array}{cccccc}\mathrm{h}_{1} & \mathrm{~h}_{2} & \mathrm{~h}_{3} & \mathrm{~h}_{4} & \ldots & \mathrm{h}_{\mathrm{t}} \\ -\mathrm{h}_{2}^{*} & -\mathrm{h}_{1}^{*} & 0 & 0 & \ldots & 0 \\ \mathrm{~h}_{3}^{*} & 0 & -\mathrm{h}_{1}^{*} & 0 & \ldots & 0 \\ \mathrm{~h}_{4}^{*} & 0 & 0 & -\mathrm{h}_{1}^{*} & \ldots & 0\end{array}\right]$

Step5: Then we add a row to make second and third column orthogonal and so on. This process is continued until the whole matrix become orthogonal.

$$
\left[\begin{array}{ccccccc}
\mathrm{h}_{1} & \mathrm{~h}_{2} & \mathrm{~h}_{3} & \mathrm{~h}_{4} & \ldots & \mathrm{h}_{\mathrm{t}-1} & \mathrm{~h}_{\mathrm{t}} \\
-\mathrm{h}_{2}^{*} & -\mathrm{h}_{1}^{*} & 0 & 0 & \ldots & 0 & 0 \\
\mathrm{~h}_{3}^{*} & 0 & -\mathrm{h}_{1}^{*} & 0 & \ldots & 0 & 0 \\
\mathrm{~h}_{4}^{*} & 0 & 0 & -\mathrm{h}_{1}^{*} & \ldots & 0 & 0 \\
: & : & : & : & : & 0 & 0 \\
: & : & : & : & : & : & \vdots \\
0 & 0 & 0 & 0 & \ldots & \mathrm{h}_{\mathrm{t}}^{*} & -\mathrm{h}_{\mathrm{t}-1}^{*}
\end{array}\right]
$$

No of rows required $=$ no. of time intervals, required to transmit $\mathrm{t}$ symbols.

Orthogonal requirement for $\mathrm{H}$ matrix: 
This process satisfies the orthogonality requirements for $\mathrm{H}$ matrix (channel matrix) the no. of rows provides the no. of time intervals needed to transmit $t$ no. of symbols. Now, starting with the first row, add (k-1) rows so that the first column is orthogonal to column 2 , then we add (k-2) rows, so that the 2 nd column is orthogonal to column 3 and so on. Therefore, total number of rows present in the channel matrix

$$
1+\sum_{\mathrm{k}=1}^{\mathrm{t}-1} \mathrm{k}=1+\frac{\mathrm{t}(\mathrm{t}-1)}{2}=\frac{\mathrm{t}^{2}-\mathrm{t}+2}{2}
$$

Step 1: The equation relating input and output by involving $\mathrm{H}$ matrix is given by

$\mathrm{Y}=\mathrm{Hx}+\eta$

$$
\begin{aligned}
& {\left[\begin{array}{c}
\mathrm{y}_{1} \\
\mathrm{y}_{2}^{*} \\
\mathrm{y}_{3}^{*} \\
\mathrm{y}_{4}^{*} \\
\mathrm{y}_{5}^{*} \\
\vdots \\
\vdots \\
\mathrm{y}_{\left(\frac{\mathrm{t}^{2}-\mathrm{t}+2}{2}\right)}^{*}
\end{array}\right]=\left[\begin{array}{ccccccc}
\mathrm{h}_{1} & \mathrm{~h}_{2} & \mathrm{~h}_{3} & \mathrm{~h}_{4} & \ldots & \mathrm{h}_{\mathrm{t}-1} & \mathrm{~h}_{\mathrm{t}} \\
-\mathrm{h}_{2}^{*} & \mathrm{~h}_{1}^{*} & 0 & 0 & \ldots & 0 & 0 \\
-\mathrm{h}_{3}^{*} & 0 & \mathrm{~h}_{1}^{*} & 0 & \ldots & 0 & 0 \\
-\mathrm{h}_{4}^{*} & 0 & 0 & \mathrm{~h}_{1}^{*} & \ldots & 0 & 0 \\
\vdots & : & : & : & : & 0 & 0 \\
\vdots & : & \vdots & \vdots & : & \vdots & \vdots \\
0 & 0 & 0 & 0 & \ldots & -\mathrm{h}_{\mathrm{t}}^{*} & \mathrm{~h}_{\mathrm{t}-1}^{*}
\end{array}\right]\left[\begin{array}{c}
\mathrm{x}_{1} \\
\mathrm{x}_{2} \\
\mathrm{x}_{3} \\
\mathrm{x}_{4} \\
\vdots \\
\mathrm{x}_{\mathrm{t}}
\end{array}\right]+} \\
& {\left[\begin{array}{c}
\mathrm{n}_{1} \\
\mathrm{n}_{2}^{*} \\
\mathrm{n}_{3}^{*} \\
\mathrm{n}_{4}^{*} \\
\mathrm{n}_{5}^{*} \\
\vdots \\
\vdots \\
\mathrm{n}_{\left(\frac{\mathrm{t}^{2}-\mathrm{t}+2}{2}\right)}^{*}
\end{array}\right]}
\end{aligned}
$$

Step 2: The received signal $\tilde{\mathrm{x}}$ can be obtained by the equation:

\section{Two Transmitter-Two Receiver Scheme}

$$
\begin{aligned}
& \tilde{x}=H H y=H H[H x+\eta] \\
& {\left[\begin{array}{c}
\tilde{\mathrm{x}}_{1} \\
\tilde{\mathrm{x}}_{2} \\
\tilde{\mathrm{x}}_{3} \\
\vdots \\
\tilde{\mathrm{x}}_{\mathrm{t}}
\end{array}\right]=\mathrm{HH}\left[\begin{array}{c}
\mathrm{y}_{1} \\
\mathrm{y}_{2}^{*} \\
\mathrm{y}_{3}^{*} \\
\mathrm{y}_{4}^{*} \\
\mathrm{y}_{5}^{*} \\
\vdots \\
\vdots \\
\mathrm{y}_{\left(\frac{\mathrm{t}^{2}-\mathrm{t}+2}{2}\right)}^{*}
\end{array}\right]=} \\
& {\left[\begin{array}{ccccccc}
\mathrm{h}_{1}^{*} & -\mathrm{h}_{2} & \mathrm{~h}_{3} & \mathrm{~h}_{4} & \ldots & 0 & 0 \\
\mathrm{~h}_{2}^{*} & \mathrm{~h}_{1} & 0 & 0 & \ldots & 0 & 0 \\
\mathrm{~h}_{3}^{*} & 0 & \mathrm{~h}_{1} & 0 & \ldots & 0 & 0 \\
\mathrm{~h}_{4}^{*} & 0 & 0 & \mathrm{~h}_{1} & \ldots & 0 & 0 \\
\vdots & : & : & : & : & 0 & 0 \\
\mathrm{~h}_{\mathrm{t}-1}^{*} & \vdots & : & : & : & : & -\mathrm{h}_{\mathrm{t}} \\
\mathrm{h}_{\mathrm{t}}^{*} & 0 & 0 & 0 & \ldots & 0 & \mathrm{~h}_{\mathrm{t}-1}
\end{array}\right]\left[\begin{array}{c}
\mathrm{y}_{1} \\
\mathrm{y}_{2}^{*} \\
\mathrm{y}_{3}^{*} \\
\mathrm{y}_{4}^{*} \\
\mathrm{y}_{5}^{*} \\
\vdots \\
\vdots \\
\mathrm{y}_{\left(\frac{\mathrm{t}^{2}-\mathrm{t}+2}{2}\right)}^{*}
\end{array}\right]+}
\end{aligned}
$$$$
\eta
$$

Noise is given by the equation $\eta=\mathrm{H}^{\mathrm{H}} \mathrm{n}$

Step 3: Thus each symbol (estimated) will be given by

$$
\begin{aligned}
& \widetilde{x_{1}}=\left(\left|h_{1}\right|^{2}+\left|h_{2}\right|^{2}+\left|h_{3}\right|^{2}+\left|h_{4}\right|^{2}+\ldots+\left|h_{t}\right|^{2}\right) x_{1}+\eta_{1} \\
& \widetilde{x_{2}}=\left(\left|h_{1}\right|^{2}+\left|h_{2}\right|^{2}+\left|h_{3}\right|^{2}+\left|h_{4}\right|^{2}+\ldots+\left|h_{t}\right|^{2}\right) x_{2}+\eta_{2}
\end{aligned}
$$

$$
\widetilde{x_{t}}=\left(\left|h_{1}\right|^{2}+\left|h_{2}\right|^{2}+\left|h_{3}\right|^{2}+\left|h_{4}\right|^{2}+\ldots+\left|h_{t}\right|^{2}\right) x_{t}+\eta_{t}
$$

From the above equation it can be justified that as space diversity increases the amplitude of the received (estimated) signal amplitude increases thus improved BER can be achieved.

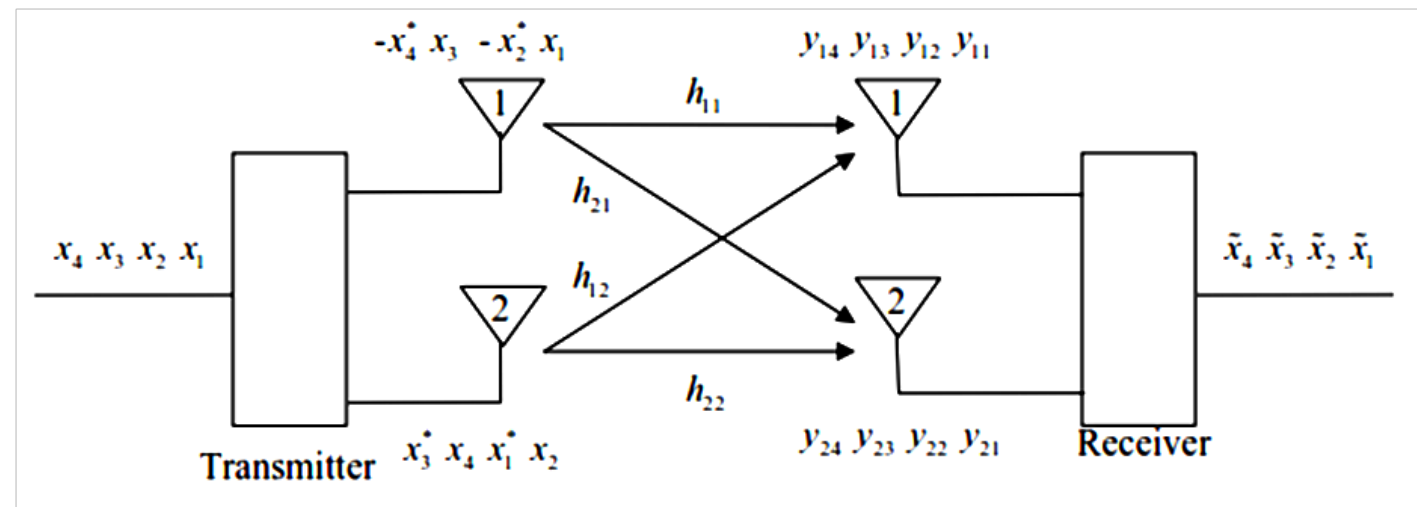

Fig 3 Two transmitter-Two receiver scheme

In Two transmitter-two receiver scheme, the diversity gain is two times than that of Two transmitter-one receiver scheme, since four different paths are available [12]. Designing the system and preserving orthogonal property. 
Antenna 1 transmits signal $\mathrm{x} 1$ and Antenna 2 transmit signal $\mathrm{x} 2$ during the first time interval. During second time interval signals $-\mathrm{x} 2 *$ and $\mathrm{x} 1 *$ are transmitted by the antennas 1 and 2 respectively, as in this scheme two sending and two receiving antenna are available. Now for antennal at the receiving side, received signal y11 is combination of two signals $\mathrm{x} 1$ and $\mathrm{x} 2$ which is transmitted during the first time slot. Received signal y12 is combination of two signal $-\mathrm{x} 2 *$ and $\mathrm{x} 1 *$ transmitted during second time slot and hence forth. The received signals are,

$$
\mathrm{Y} 11=\mathrm{h} 11 \mathrm{x} 1+\mathrm{h} 12 \times 2+\mathrm{n} 1
$$

$$
\begin{gathered}
\mathrm{Y} 12=\mathrm{h} 11(-\mathrm{x} 2 *)+\mathrm{h} 12 \mathrm{x} 1 *+\mathrm{n} 2 \\
\mathrm{Y} 21=\mathrm{h} 21(\mathrm{x} 1)+\mathrm{h} 22(\mathrm{x} 2)+\mathrm{n} 3 \\
\mathrm{Y} 22=\mathrm{h} 21(-\mathrm{x} 2 *)+\mathrm{h} 22(\mathrm{x} 1 *)+\mathrm{n} 4
\end{gathered}
$$

Representation in matrix form

$$
\left[\begin{array}{ll}
\mathrm{y}_{11} & \mathrm{y}_{12} \\
\mathrm{y}_{21} & \mathrm{y}_{22}
\end{array}\right]=\left[\begin{array}{ll}
\mathrm{h}_{11} & \mathrm{~h}_{12} \\
\mathrm{~h}_{21} & \mathrm{~h}_{22}
\end{array}\right]\left[\begin{array}{cc}
\mathrm{x}_{1} & -\mathrm{x}_{2}^{*} \\
\mathrm{x}_{2} & \mathrm{x}_{1}^{*}
\end{array}\right]+\left[\begin{array}{ll}
\mathrm{n}_{1} & \mathrm{n}_{2} \\
\mathrm{n}_{3} & \mathrm{n}_{4}
\end{array}\right]
$$

Another form of writing this equation

$$
\left[\begin{array}{l}
y_{11} \\
y_{12}^{*} \\
y_{21} \\
y_{22}^{*}
\end{array}\right]=\left[\begin{array}{cc}
h_{11} & h_{12} \\
h_{12}^{*} & -h_{11}^{*} \\
h_{21} & h_{22} \\
h_{22}^{*} & -h_{21}^{*}
\end{array}\right]\left[\begin{array}{l}
x_{1} \\
x_{2}
\end{array}\right]+\left[\begin{array}{c}
n_{1} \\
n_{2}^{*} \\
n_{3} \\
n_{4}^{*}
\end{array}\right]
$$

At the receiver similar relation is used to decode and calculate the transmitted signals, the symbols (estimated) $\widetilde{\mathrm{x}_{1}}$ and $\widetilde{\mathrm{x}_{2}}$ can be calculated

$$
\begin{aligned}
& \widetilde{\mathrm{x}_{1}}=\mathrm{h}_{11}{ }^{*} \mathrm{y}_{11}+\mathrm{h}_{12} \mathrm{y}_{12}{ }^{*}+\mathrm{h}_{21}{ }^{*} \mathrm{y}_{21}+\mathrm{h}_{22} \mathrm{y}_{22}{ }^{*} \\
& \widetilde{\mathrm{x}_{2}}=\mathrm{h}_{12}{ }^{*} \mathrm{y}_{11}-\mathrm{h}_{11} \mathrm{y}_{12}{ }^{*}+\mathrm{h}_{22}{ }^{*} \mathrm{y}_{21}-\mathrm{h}_{21} \mathrm{y}_{22}{ }^{*}
\end{aligned}
$$

The receiver uses a decoding algorithm which is similar to encoding algorithm.

$$
\begin{aligned}
& \widetilde{x_{1}}=\left(\left|h_{11}\right|^{2}+\left|h_{12}\right|^{2}+\left|h_{21}\right|^{2}+\left|h_{22}\right|^{2}\right) x_{1}+\eta 1 \\
& \widetilde{x_{2}}=\left(\left|h_{11}\right|^{2}+\left|h_{12}\right|^{2}+\left|h_{21}\right|^{2}+\left|h_{22}\right|^{2}\right) x_{2}+\eta 2
\end{aligned}
$$

and the noise terms are

$$
\begin{aligned}
& \eta 1=\mathrm{h}_{11}{ }^{*} \mathrm{n}_{1}+\mathrm{h}_{12} \mathrm{n}_{2}{ }^{*}+\mathrm{h}_{21}{ }^{*} \mathrm{n}_{3}+\mathrm{h}_{22} \mathrm{n}_{4}{ }^{*} \\
& \eta 2=\mathrm{h}_{12}{ }^{*} \mathrm{n}_{1}-\mathrm{h}_{11} \mathrm{n}_{2}{ }^{*}+\mathrm{h}_{22}{ }^{*} \mathrm{n}_{3}-\mathrm{h}_{21} \mathrm{n}_{4}{ }^{*}
\end{aligned}
$$

The rate will remain constant (maximum rate $=1$ ) if the no. of transmitting antennas are fixed at two. As two time slots are required to send two bits. Thus full rate is achieved. The number of transmitting antenna can be increased which increases the transmission diversity [13]. In order to maintain orthoganality, Three bits requires four time slots thus can achieve maximum rate of $3 / 4$ [2]. The design process maintains orthogonal relationship between the channels by properly designing the channel matrix.

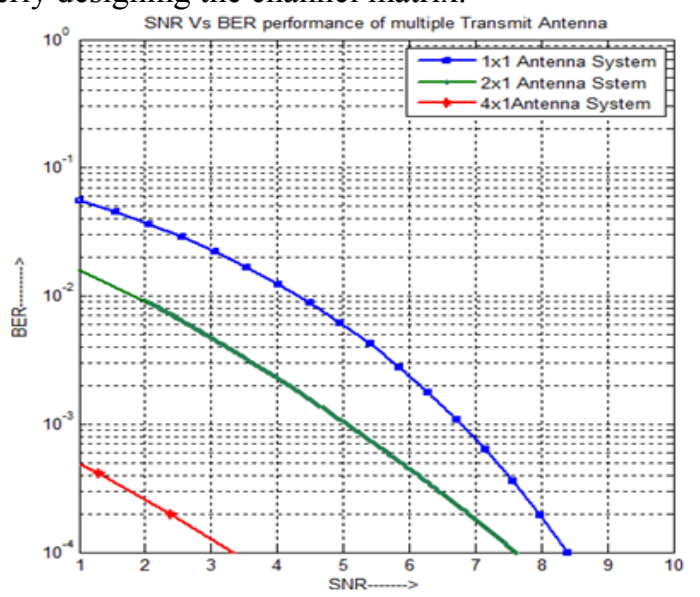

Fig. 1 Graph between SNR Vs BER of Multiple transmit Antenna System

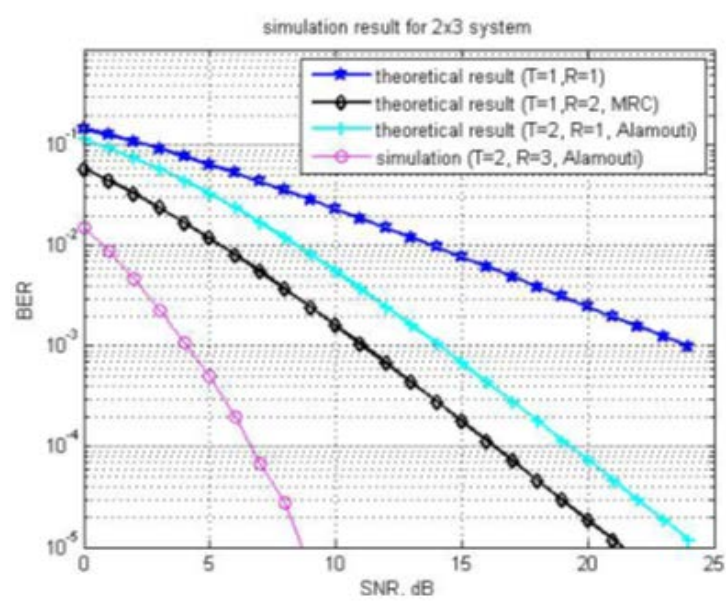

Fig. 2 Graphs between SNR Vs BER of Orthogonal STBC System

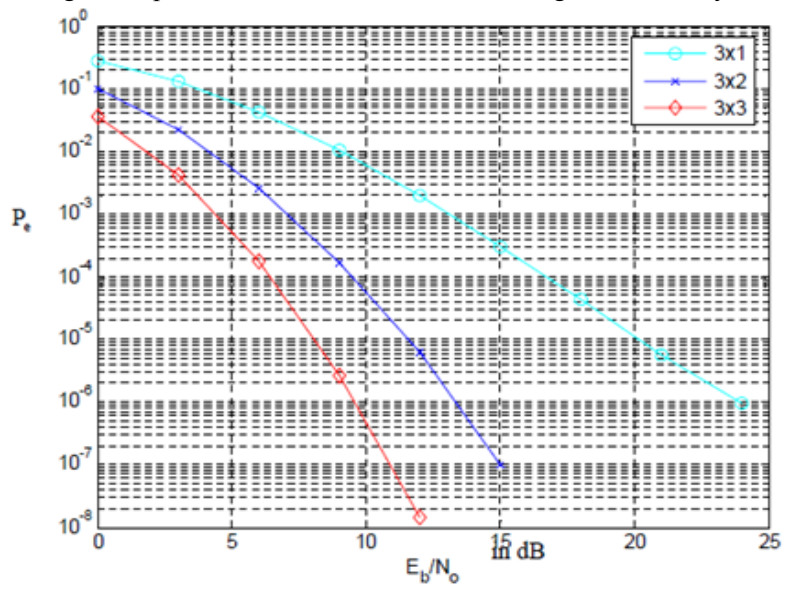

Fig. 3 Graph between SNR Vs BER of Orthogonal STBC Multiple Antenna System

\section{CONCLUSION}

This paper investigated the performance of MIMO systems that use STBC. Such systems can be employed to improve the BER performance of wireless communication systems 
and can counter the detrimental effects of channel fading and other distortion phenomena. A variety of different MIMO schemes were evaluated in simulation using the MATLAB programming language. MIMO systems can also be used to counter the performance degradation that results from correlation between multipath channels at a receiver. This paper analyzed the relationship between channel correlation coefficients and antenna spacing through simulation.

Result: This paper involves a systematic method for designing a M IMO system with an STBC, the arbitrary number of transmit and receive antennas. Simulation results were used to evaluate the performance of MIMO-STBC systems designed using our approach, in Rayleigh fading channels. We presented a formula that can be readily used to determine the rate (i.e., the ratio of the number of symbols transmitted over the number of symbol intervals required) of systems that employ our design. Three criteria-the rate of the scheme, the BER and the complexity were used to analyze our scheme.

\section{REFERENCES}

[1] S. M. Alamouti, "A simple transmit diversity technique for wireless communications", IEEE Journal on selected areas in communications, Vol.16, No. 8, pp. 1451-1458, 1998.

[2] V. Tarokh, H. Jafarkhani and A. R. Calderbank, "Space-time block codes from orthogonal designs", IEEE Transactions on Information theory, Vol.45, No. 5, pp. 1456-1467, 1999.

[3] H. Jafarkhani, "A quasi-orthogonal space-time block code", IEEE Transactions on Communications, Vol.49, No. 1, pp. 1-4, 2001.
[4] L. Zheng and D. N. C. Tse, "Diversity and multiplexing: A fundamental tradeoff in multiple-antenna channels", IEEE Transactions on information theory, Vol.49, No. 5, 1073-1096, 2003.

[5] A. J. Paulraj, D. A. Gore, R. U. Nabar and Bolcskei, "HAn overview of MIMO communications-a key to gigabit wireless", Proceedings of the IEEE, Vol. 92, No. 2,pp. 198-218, 2004.

[6] F. Oggier, G. Rekaya, J. C. Belfiore and E. Viterbo, "Perfect spacetime block codes". IEEE Transactions on information theory, Vol.52, No. 9, pp. 3885-3902, 2006.

[7] M. R. Bhatnagar, R. Vishwanath and V. Bhatnagar, "Performance analysis of space-time block codes in flat fading MIMO channels with offsets", EURASIP Journal on Wireless Communications and Networking, Vol. 1, pp. 4-4, 2007

[8] K. S. Nobandegani and P. Azmi, "A New Linear Space-Time Block Code for Wireless Channels with Correlated Fading Coefficients", Progress In Electromagnetics Research C, Vol. 1, pp. 211-228, 2008.

[9] E. Biglieri, Y. Hong and E. Viterbo, "On fast-decodable space-time block codes", IEEE Transactions on Information Theory, Vol. 55, No. 2, 524-530, 2009.

[10] A. Moldovan, T. Palade, E. Puschita, I. Vermesan and R. Colda, , "Performance evaluation of STBC MIMO systems with linear precoding", In 17th Telecommunications forum TELFOR, pp. 24-26, 2009.

[11] M. A. I.Jewel and M. Rahman, "Full rate general complex orthogonal space-time block code for 4-transmit antenna", In Wireless Communications, Networking and Mobile Computing, WiCom'09. 5th International Conference on IEEE, pp. 1-4, 2009.

[12] E. Basar, U. Aygolu, E. Panayirci and H. V. Poor, "Space-time block coded spatial modulation", IEEE Transactions on Communications, Vol. 59, No. 3, pp. 823-832, 2011.

[13] A. G. Wadday, S. A. Alseyab and A. S. Abdullah, "Capacity Improvement of Space Time Block Code Spatial Modulation for Three Transmit Antennas", Journal of Information Processing and Management, Vol. 3, No. 1, pp. 70-78,2012. 